\title{
C-type natriuretic peptide and its contribution to bone growth
}

\author{
Beata Kulik-Rechberger ${ }^{1, A-F}{ }^{\oplus}$, Maria Trojanowska-Szostek ${ }^{1, C-F} \oplus$ \\ 1 Department of Paediatric Propedeutics, Medical University, Lublin, Poland \\ A - Research concept and design, B - Collection and/or assembly of data, C - Data analysis and interpretation, \\ $D$ - Writing the article, E-Critical revision of the article, F- Final approval of the article
}

Kulik-Rechberger B, Trojanowska-Szostek M. C-type natriuretic peptide and its contribution to bone growth. Ann Agric Environ Med. 2022; 29(2): 252-257. doi: 10.26444/aaem/140076

\begin{abstract}
I Abstract
Introduction and objective. The expression of the C-type natriuretic peptide (CNP) gene has been detected in the growth cartilage of the long bones and vertebrae. This article provides an overview of the role of CNP in bone growth and presents the results of the authors' research on the concentration of the NTproCNP and its relationship with growth velocity and bone markers in healthy school-age children.

Materials and method. The study involved 75 girls and 59 boys aged from $9.0-11.8$ years (mean $10.29 \pm 0.74$ ). Body weight, height and lower limb length were measured, and blood samples were collected twice at six-month intervals. In the first serum sample, the concentrations of NTproCNP, C-terminal propeptide type I (CICP), C-terminal telopeptide type I collagen (ICTP) osteocalcin (OC) and bone-specific alkaline phosphatase (BAP) were determined. In the second sample, NTproCNP concentration was assessed.

Results. During the six-month follow-up period, the increase in body height and weight of girls was greater than boys $(p<0.000 ; p=0.003$, respectively). While during the first examination the concentration of NTproCNP in girls and boys was similar, during the second examination it was higher in girls than in boys $(p=0.04)$. Weak positive correlations between the increase in body height and NTproCNP, CICP, BAP as well as OC were found. There were no correlations between NTproCNP and the bone markers.

Conclusions. The results suggest that NTproCNP concentration depends on growth velocity in children. There is increasing evidence that a better knowledge of CNP biology contributes to a better understanding of bone growth mechanisms.
\end{abstract}

\section{Key words}

children, growth, bone metabolism, C-type natiuretic peptide

\section{Abbreviations}

AMDM - acromesomelic dysplasia Maroteaux type; BAP - bone-specific alkaline phosphatase; B-boys; BMI - body mass index; BMPs - bone morphogenetic proteins; CICP - C-terminal pro-collagen-type I propeptide; CNP - C-type natriuretic peptide; FGFR3 - fibroblast growth factor receptor 3; FGFs - fibroblast growth factors; G-girls; GC-B - guanylate cyclase B; ICTP - C-terminal telopeptide type I collagen; IGFs - insulin-like growth factors; IHH - indian hedgehog homolog; NPPC - natriuretic peptide precursor C; NPR-A - natriuretic peptide receptor-A; NPR-B - natriuretic peptide receptor-B; NPR-C - natriuretic peptide receptor-C; NTproCNP - amino-terminal propeptide of the C-type natriuretic peptide; OC osteocalcin; preproCNP - C-type natriuretic peptide prepropeptide; pro-CNP - C-type natriuretic peptide propeptide; PTHrP - parathyroid hormone-related peptide; VEGF - vascular endothelial growth factor.

\section{INTRODUCTION AND OBJECTIVE}

Bone growth in length is possible due to the epiphyseal cartilage (growth plate) located between the epiphysis and the metaphysis of the bone. The proliferation of chondrocytes, their expansion and subsequent replacement by osteoblasts, make the bone grow in length. This process is determined by genetic factors, hormones, and auto/paracrine-acting growth factors. Among them, there are mentioned growth hormone, thyroid hormones, oestrogens and androgens as well as insulin-like growth factors (IGFs), fibroblast growth factors (FGFs), the indian hedgehog homolog (IHH), parathyroid hormone-related peptide (PTHrP), bone morphogenetic proteins (BMPs), signal molecules belonging to the WNT protein family, vascular endothelial growth factor (VEGF), as well as C-type natriuretic peptide (CNP) $[1,2,3,4]$. CNP

Address for correspondence: Beata Kulik-Rechberger, Department of Paediatric Propedeutics, Medical University of Lublin, Poland

E-mail: brechberger@interia.pl

Received: 13.05.2021; accepted: 08.07.2021; first published: 26.07.2021 is one of the human natriuretic peptides with a relatively weak (in physiological concentration) diuretic action $[1,5]$. The gene encoding human CNP, named as NPPC (natriuretic peptide precursor C), contains two exons and is located on chromosome 2 (2q37.1) (http://www.genecards.org). Its relatively high level of expression has been detected (among others) in proliferating and pre-hypertrophic chondrocytes of the growth cartilage of the long bones, spine vertebrae, and facial bones $[5,6]$. The product of the NPPC gene is the 126-amino acid CNP prepropeptide (preproCNP), from which the 103-amino acid CNP propeptide (pro-CNP) is produced with the participation of the serine protease. From it CNP is synthesized trough hydrolysis. Both CNP and proCNP circulate in the bloodstream, but the half-life of proCNP is longer and its blood concentration is $20-50$ times higher than the concentration of CNP. It is also more stable, does not show daily fluctuations or dependence on consumed meals $[7,8]$.

Among three different receptors [natriuretic peptide receptor-A (NPR-A), natriuretic peptide receptor-B (NPR-B), 
natriuretic peptide receptor-C (NPR-C)], NPR-B, also known as guanylate cyclase $\mathrm{B}$ (GC-B), exhibits the highest affinity for CNP [9]. The gene encoding NPR-B, known as NPR2, is located on the chromosome 9p13.3 (http://www.genecards.org). Its expression has been identified in bone growth cartilage (in the proliferative and hypertrophic layers of chondrocytes), but also in the brain, heart, kidneys, adrenal glands, liver, lungs, uterus or smooth muscle of blood vessels $[10,11]$. Experimental studies show that CNP, via the NPR-B receptor, stimulates chondrocytes proliferation, increases the synthesis of the cartilage intercellular matrix and the growth plate cells hypertrophy $[12,13]$. Genetic abnormalities involving CNP or NPR-B result in skeletal growth disorders. Thus, transgenic mice with overexpressing NPPC and excessive synthesis of CNP and mice with impaired CNP degradation caused by decreased function of NPR-C (receptor removing natriuretic peptides from the bloodstream and extracellular environment), have skeletal hypertrophy [14]. In turn, mice with mutation in NPPC and with reduced CNP synthesis, as well as with mutation in NPR2 gene and with reduced NPR-B receptor activity, have skeleton hypoplasia $[15,16,17]$. Histology indicates a significant reduction of the proliferating layer and hypertrophic chondrocytes in the growth bone plate [13].

In humans, a homozygous mutation leading to the loss of the NPR2 gene function causes the acromesomelic dysplasia Maroteaux type (AMDM; MIM\# 602875). This is an autosomal recessive disorder belonging to the group of acromesomelic dysplasias. Patients affected with AMDM are significantly shorter than their peers, have shortening of the middle and distal parts of the limbs (forearms, hands, shins, and feet). Adult heights may be more than 5 SD below the mean [18, $19,20]$. The heterozygous mutation of NPR2 leading to the reduction of gene expression, does not cause such drastic phenotypic effects. People affected by it have a short final height, but the condition itself may be variously intensified $[21,22]$. In turn, increased expression of the NPPC gene (increased CNP synthesis), as well as the NPR2 gene (NPR-B hyperactivity), resulting from chromosomal translocation, causes excessive skeletal growth. For example, patients with a translocation in the $2 \mathrm{q} 37$ chromosome that overexpress the NPPC gene are tall, have a marfanoid body structure and increased CNP concentration in the blood [11, 23, 24]. The above-mentioned evidence indicates that the process of bone growth is conditioned by a properly functioning CNP/ NPR-B system; thus, in some clinical cases, CNP, or a more stable proCNP, could be a marker of its intensity.

Among the first researchers who noted the usefulness of the NTproCNP blood tests to monitor the growth process were Prickett and co-authors [8, 25]. They indicated the relationship between NTproCNP and selected indicators of bone metabolism [8] which are also used to monitor growth. These include C-terminal pro-collagen type I propeptide (CICP), bone-specific alkaline phosphatase (BAP), osteocalcin (OC) and C-terminal telopeptides of type I collagen (ICTP) [26, 27, 28, 29, 30, 31, 32]. C- and $\mathrm{N}$-terminal pro-collagen type I propeptides are proteins released by osteoblasts during the synthesis of type I collagen, accumulated in the extracellular matrix of the bone. BAP and OC are also released by osteoblasts and participate in the formation of osteoid and bone mineralization. In addition, OC is synthesized by hypertrophic chondrocytes of the epiphyseal cartilage. ICTP is an indicator of the intensity of bone resorption, which is an inherent element of the process called bone turnover. The aim of this study was to describe the role of CNP in bone growth and to assess the concentration of the NTproCNP and its relationship with growth velocity and concentration of selected bone markers in healthy school-age children.

\section{MATERIALS AND METHOD}

The study involved 134 healthy children (75 girls and 59 boys) between $9.0-11.8$ years of age (mean $10.29 \pm 0.74$ ) from the Lublin region of eastern Poland who took part in a nationwide project for evaluation of vitamin $\mathrm{D}$ status in children (RNN/7/10/KE) [33]. Exclusion criteria were diseases affecting bone health, such as nutritional disorders, diseases of the digestive system, kidney disease, endocrine diseases, and glucocorticoid use. The children were examined twice in an interval of six months in a school nurses' office. Each time their health was assessed, medical history collected and a physical examination performed. Body weight, body height, and lower limb length (basis-symphysion) were determined by the same anthropologist, according to standardized techniques. In girls, pubertal stage were assigned by physical examination, according to the Tanner criteria for breast development. They were also asked about their first menstruation. In boys, instead of physical examinations, the self-assessment of the pubertal stage according to the Tanner scale was used.

Twice, at the beginning and the end of observation, (between 08:00 - 10:00 h), blood samples were taken from the antecubital vein and serum was separated. In a part of the serum samples the concentration of $25(\mathrm{OH}) \mathrm{D}$ was determined [6]. The remaining samples were stored at $-80^{\circ} \mathrm{C}$ for further analysis. In the first serum sample (first examination - I) the concentrations of the amino-terminal propeptide of the C-type natriuretic peptide (NT-proCNP ELISA Eagle Bioscience, Inc.), C-terminal pro-collagen-type I propeptide (MicroVue CICP ELISA kit, Quidel Corporation), C-terminal telopeptide of collagen type I (Serum CrossLaps ELISA; Immune Diagnostic Systems), osteocalcin (Human Osteocalcin (1-43 / 49); Epitope Diagnostics, Inc.) and bonespecific alkaline phosphatase (Ostase BAP EIA; Immune Diagnostic Systems) were determined. In the second serum sample (second examination - II), only the concentration of NT-proCNP was determined.

The children were divided into two gender groups. The normality of distributions of the studied variables was assessed with the use of the Shapiro-Wilk test. The significance of differences between the mean values of anthropometric features, as well as biochemical parameters in the analysed groups, was assessed using Mann-Whitney U test (nonparametric test for unrelated variables). The significance of differences within the same group was measured using the Wilcoxon test (a non-parametric test for related variables). To measure the degree of relationship between variables the Spearman correlation was used. The level of significance was assumed at $\mathrm{p}<0.05$. Statistical analyses were carried out using the STATISTICA v6.0 computer software (StatSoft, Poland). The research was approved by the Bioethical Commission at the Medical University in Lublin, Poland (KE-0254/323/2015). 


\section{RESULTS}

At the time of the first examinations, the age of girls and boys did not differ. There were also no differences between the somatic features of girls and boys. They had similar body height, weight and length of lower limbs (Tab.1). On assessing the pubertal stages of girls, it was found that 42 of them were in stage I, 26 in stage II, and 7 in stage III. All were before menarche. In boys, only 3 were in the stage II and no one on stage III or more. The 6-month observation period showed that the girls' growth rate was faster than that of boys. Their body weight and height increases were greater (respectively: $\mathrm{p}<0.0001 ; \mathrm{p}=0.003$ ), but there was no difference in the increase in the length of the lower limbs (Tab. 1).

In the first and the second examination, neither in the group of girls nor in the group of boys, were the differences between the NTproCNP concentrations statistically significant (Tab. 2). While during the first examination, the concentration of NTproCNP in girls was similar to that of boys, during the second examination, it was significantly higher in girls $(\mathrm{p}=0.043)$. They also had a significantly higher BAP concentration than the boys $(p=0.033)$. The concentrations of other bone markers did not differ significantly (Tab. 2). There were weak positive correlations between the body height increase and serum concentrations of NTproCNP, CICP, BAP as well as OC (Tab. 3). There was no correlation between the concentrations of analysed bone markers and NTproCNP, nor between BMI and NTproCNP concentration.

\section{DISCUSSION}

The basic condition for proper bone growth is the correct synthesis of biologically-active substances and the presence of specific receptors in the target tissue - the growth cartilage. The role of CNP in bone growth is not fully understood. This study determined the relationship between NT-proCNP concentration and the rate of growth of school-age healthy children. The children ranged from $9-11.8$ years of age, and were observed for six months. On comparing the increase in their body weight and height, it was found that these

Table 1. Characteristics of girls $(n=75)$ and boys $(n=59)$

\begin{tabular}{|c|c|c|c|c|c|}
\hline & $\begin{array}{c}\text { Girls }(G) n=75 \\
\text { mean } \pm S D\end{array}$ & median & $\begin{array}{c}\text { Boys }(B) n=59 \\
\text { mean } \pm S D\end{array}$ & median & $\begin{array}{c}\text { G vs B } \\
\text { p-value }\end{array}$ \\
\hline Age (years) & $10.25 \pm 0.71$ & 10.32 & $10.34 \pm 0.78$ & 10.5 & ns \\
\hline Body height $(\mathrm{cm})$ & $141.86 \pm 8.71$ & 141.4 & $142.79 \pm 6.54$ & 142.0 & ns \\
\hline Length of lower limbs $(\mathrm{cm})$ & $74.73 \pm 4.99$ & 74.4 & $74.66 \pm 4.03$ & 74.4 & ns \\
\hline BMI $\left(\mathrm{kg} / \mathrm{m}^{2}\right)$ & $17.72 \pm 3.61$ & 16.94 & $17.79 \pm 3.20$ & 17.56 & ns \\
\hline \multicolumn{6}{|l|}{ Increase in 6-month period } \\
\hline body weight (kg) & $2.63 \pm 1.79$ & 2.50 & $1.77 \pm 1.82$ & 1.60 & $p=0.003$ \\
\hline body height $(\mathrm{cm})$ & $2.86 \pm 0.96$ & 2.85 & $2.24 \pm 0.90$ & 2.10 & $p=0.0001$ \\
\hline Length of lower limbs (cm) & $1.89 \pm 0.91$ & 1.80 & $1.72 \pm 0.88$ & 1.70 & ns \\
\hline
\end{tabular}

SD - standard deviation; ns - not statistically significant

Table 2. Serum concentrations of CNP propeptide (NTproCNP) and C-terminal pro-collagen type I propeptide (CICP), C-terminal telopeptide type I collagen (ICTP), bone-specific alkaline phosphatase (BAP) and osteocalcin (OC) in children

\begin{tabular}{|c|c|c|c|c|c|c|}
\hline & \multicolumn{2}{|c|}{ Girls (G) } & \multicolumn{2}{|c|}{ Boys (B) } & \multirow{2}{*}{$\begin{array}{c}\text { G vs B } \\
\end{array}$} & \multirow{2}{*}{$\begin{array}{c}\text { G vs B } \\
\|\end{array}$} \\
\hline & $\begin{array}{c}\text { I } \\
\text { mean } \pm S D\end{array}$ & $\begin{array}{c}\| \\
\text { mean } \pm S D\end{array}$ & $\begin{array}{c}\text { I } \\
\text { mean } \pm S D\end{array}$ & $\begin{array}{c}\| \\
\text { mean } \pm S D\end{array}$ & & \\
\hline \multirow{2}{*}{ NTproCNP (pmol/l) } & $9.39 \pm 2.52$ & $9.96 \pm 2.66$ & $8.78 \pm 2.49$ & $8.86 \pm 2.63$ & \multirow{2}{*}{ ns } & \multirow{2}{*}{$p=0.043$} \\
\hline & \multicolumn{2}{|c|}{ | vs || - ns } & \multicolumn{2}{|c|}{ | vs II - ns } & & \\
\hline $\mathrm{CICP}(\mathrm{ng} / \mathrm{ml})$ & $355.52 \pm 130.96$ & _- & $310.67 \pm 91.45$ & _- & ns & _- \\
\hline ICTP (ng/ml) & $1.74 \pm 0.59$ & - & $1.58 \pm 0.58$ & - & ns & - \\
\hline $\mathrm{BAP}(\mu \mathrm{g} / \mathrm{L})$ & $133.98 \pm 125.1$ & - & $94.74 \pm 57.25$ & - & $p=0.033$ & - \\
\hline $\mathrm{OC}(\mathrm{ng} / \mathrm{ml})$ & $46.78 \pm 6.79$ & - & $44.60 \pm 9.19$ & _- & ns & - \\
\hline
\end{tabular}

SD - standard deviation; ns - not statistically significant

Table 3. Correlation between serum concentration of CNP propeptide (NTproCNP) and C-terminal pro-collagen type I propeptide (CICP), C-terminal telopeptide type I collagen (ICTP), bone-specific alkaline phosphatase (BAP), osteocalcin (OC) as well as somatic features of children.

\begin{tabular}{|c|c|c|c|c|c|}
\hline & Body weight & Body height & $\mathrm{BMI}$ & Height increase & NTproCNP \\
\hline NTproCNP & ns & ns & ns & $R=0.29 ; p=0.006$ & - \\
\hline $\mathrm{CICP}$ & ns & ns & ns & $\mathrm{R}=0.31 ; \mathrm{p}=0.003$ & ns \\
\hline ICTP & ns & ns & ns & ns & ns \\
\hline BAP & ns & ns & ns & $R=0.26 ; p=0.01$ & ns \\
\hline OC & ns & ns & ns & $\mathrm{R}=0.18 ; \mathrm{p}=0.04$ & ns \\
\hline
\end{tabular}


were greater in girls than in boys, although the lower limb length increase did not differ. The NTproCNP concentration in girls was higher than in boys in the follow-up conducted six months later.

Studies on the usefulness of NT-proCNP blood concentration assays for the growth assessment are not new. In 2005, Prickett et al. noted the positive correlation between the growth rate of children with short stature and the concentration of NT-proCNP in blood [8]. These authors evaluated the concentration of NT-proCNP and CNP in girls and boys aged from 5 - 18 years. In 2007, Olney et al. studied how the process of puberty and the use of growth hormone or testosterone affect the concentration of NTproCNP in children with short stature (also idiopathic) and with constitutional delay in growth. At the beginning, all short stature children had a similar concentration of NTproCNP, which increased significantly in response to treatment; hence, the conclusion that NTproCNP can be an indicator of the effectiveness of the treatment [3]. It was also noticed that the highest concentration of CNP and NTproCNP is reached between days $7-28$ after the beginning of the treatment with the growth hormone, and then slightly decreases [34]. Olney et al., similar to the presented study, assessed the concentration of NTproCNP in healthy children [25]. They examined children and young adults (between the $2^{\text {nd }}$ month and the age of 20 years). In both genders, the concentrations of NTproCNP depended on the age of the child (it was relatively high during the infancy and pubertal period). The relationship between NTproCNP and the pubertal stage, as assessed by Tanner staging was found. It was highest in boys in the $4^{\text {th }}$ stage (around 14 years old) and in girls in the $3^{\text {rd }}$ stage (around 13 years old), therefore during the peak height velocity. Unfortunately, during examinations in the school office, there was no opportunity to check the stage of sexual maturity of the boys. Judging by the age, the majority of them were in the first stage of puberty. By assessing the girls' sexual maturity, it was established that none of them had reached menarche. Similar to Olney et al. [25], a positive albeit very weak correlation was found between the NTproCNP concentration and the rate of growth. The concentrations of the bone formation markers assessed for the current study were also positively (but weakly) correlated with the rate of growth, which is known from other publications [28, 31, 32]. There was no correlation between NTproCNP and CICP, ICTP, BAP or OC. Meanwhile, Prickett et al. showed in healthy children a strong positive correlation between concentrations of NTproCNP and BAP, as well as between concentrations of NTproCNP and ICTP [8]. The relationships between CNP and bone metabolic rates were mainly studied in animals. An example of this is the study by Kondo et al. who indicated that CNP accelerates bone remodelling and healing bone fractures [35]. It is interesting that Bükümmez et al. showed that in a mouse model of arthritis, CNP over-expression in chondrocytes could prevent growth retardation and cartilage damage. This suggests that through pharmacological or biological modulation of the CNP signaling pathway, growth cartilages can also be protected and prevent the growth retardation of patients with inflammatory joint diseases, such as juvenile idiopathic arthritis [36].

When using NTproCNP as an indicator for the assessment of bone growth, the complexity of this process should be considered. It is worth noting that the health of a child can be important when assessing the concentration of
NTproCNP in his blood. It is not about chronic diseases or chronic conditions are known to slow down growth, but also about acute and short-term illnesses. Prickett et al., investigating the concentration of NTproCNP and CNP in pre-school children with acute infection, have shown that the concentrations of both indicators are reduced, which suggests that the infection can slow down bone growth clinically unnoticeably [37]. Topçu et al. investigated the NT-proCNP plasma concentration in the overweight or obese, in comparison to normal weight children. There was no difference [38]. Then presented study also did not show a relationship between BMI and NTproCNP concentration.

Recently, the results of multicentre studies on children with achondroplasia, hypochondroplasia, and anaphoric dysplasia, have been published. They prove that such children have elevated NTproCNP plasma concentrations compared to healthy children, which can indicate the lack of sensitivity of growth cartilage on the CNP [39]. The genetic basis of most of these disorders is a gene mutation of the fibroblast growth factor receptor 3 (FGFR3), whose function is limiting cell division [40]. The activated receptor transmits the signal via the Raf-MEK-ERK signalling pathway and the task of the CNP is to inhibit this signal at the Raf enzyme level. The FGFR3 receptor mutation enhances its function. In this case, one of the treatment options may be the use of a CNP analog (vosoritide, BMN 111, ClinicalTrials.gov, NCT02055157, currently the third phase of clinical trials) that inhibits the excessive activity of the Raf-MEK-ERK pathway [41]. Another option, currently at the animal testing stage, is the modification of the CNP/NPR-B system by blocking the NPR-C and its CNP degradation properties [19].

As it appears from the literature, genetic research on $\mathrm{CNP}$ and its receptor may be useful in diagnosing not only patients with skeletal dysplasia, but also in cases of less severe disorders. This is confirmed by the studies of parents of patients with AMDM. These people are nearly $6 \mathrm{~cm}$ shorter than the average height in the population, which may be due to the heterozygous NPR2 mutation [18, 42]. Heterozygous mutation of NPR2 may also be the cause of short stature of patients with idiopathic or family short stature [22]. Olney et al. suggested that up to 1 in 30 people with idiopathic short stature may be carriers of such a mutation [21].

In view of the ever-widening possibilities of diagnosing children with short stature, one can ask whether determining the concentration of proCNP or NTproCNP can really be helpful in clinical practice. The results obtained in the current study suggest that the concentration of NTproCNP depends on the growth velocity in healthy children.

It should be noted, however, that the current study has limitations, such as the small size of the group, the inability to assess more precisely the pubertal stages of boys, and the lack of more accurate bone evaluation by methods such as bone age or densitometry. Based on the results of other authors, it can be confirmed that research on CNP is still ongoing [43]. The latest publication by Espiner, Prickett, and Olney, summarizing the past achievements of CNP participation in bone growth, proves that proCNP or NTproCNP are good indicators of this process, especially in children during treatment (including CNP analog) [7]. However, their clinical usefulness is conditioned by good knowledge of the role of $\mathrm{CNP}$, its production and function, accessibility to reliable determination methods and reference range for age and gender. 


\section{CONCLUSIONS}

The results suggest that NTproCNP concentration depends on growth velocity in healthy school-age children. There is increasing evidence that a better knowledge of CNP biology will contribute to a better understanding of bone growth mechanisms.

\section{Acknowledgements}

The authors would like to thank Dr. Maria Kozłowska, an anthropologist, for carrying out all anthropologic measurements and assistance with their interpretation. The authors also thank the children and their families for their involvement and cooperation in this study.

\section{REFERENCES}

1. Gawlik A, Mazur A. Peptydy natriuretyczne u dzieci: fizjologia i zastosowanie kliniczne. Pediatr Dypl. 2013; 17(5): 40-45

2. Lui JC, Nilsson O, Baron J. Recent research on the growth plate: Recent insights into the regulation of the growth plate. J Mol Endocrinol. 2014 Aug; 53(1): T1-9. https://doi.org/10.1530/JME-14-0022

3. Olney RC, Prickett TC, Yandle TG, et al. Amino-terminal propeptide of C-type natriuretic peptide and linear growth in children: effects of puberty, testosterone, and growth hormone. J Clin Endocrinol Metab. 2007 Nov; 92(11): 4294-8. https://doi.org/10.1210/jc.2007-0567

4. Wit JM, Oostdijk W, Losekoot M, et al. Mechanisms in endocrinology: Novel genetic causes of short stature. Eur J Endocrinol. 2016 Apr; 174(4): R145-73. https://doi.org/10.1530/EJE-15-0937

5. Prickett TC, A Espiner E. Circulating products of C-type natriuretic peptide and links with organ function in health and disease. Peptides. 2020 Oct; 132: 170363. https://doi.org/10.1016/j.peptides.2020.170363

6. Chen WX, Liu HH, Li RX, et al. C-type natriuretic peptide stimulates osteoblastic proliferation and collagen-X expression but suppresses fibroblast growth factor-23 expression in vitro. Pediatr Rheumatol Online J. 2020 Jun 9; 18(1): 46. https://doi.org/10.1186/s12969-020-00441-w

7. Espiner E, Prickett T, Olney R. Plasma C-Type Natriuretic Peptide: Emerging Applications in Disorders of Skeletal Growth. Horm Res Paediatr. 2018; 90(6): 345-357. https://doi.org/10.1159/000496544

8. Prickett TC, Lynn AM, Barrell GK, et al. Amino-terminal proCNP: a putative marker of cartilage activity in postnatal growth. Pediatr Res. 2005 Aug; 58(2): 334-40. https://doi.org/10.1203/01. PDR.0000169964.66260.4B

9. Suga S, Nakao K, Hosoda K, et al. Receptor selectivity of natriuretic peptide family, atrial natriuretic peptide, brain natriuretic peptide, and C-type natriuretic peptide. Endocrinology. 1992 Jan; 130(1): 229-39. https://doi.org/10.1210/endo.130.1.1309330

10. Sangaralingham SJ, Burnett JC Jr. Relaxing With C-Type Natriuretic Peptide, the Guanylyl Cyclase B Receptor, and Pericytes. Circulation. 2018 Jul 31; 138(5): 509-512. https://doi.org/10.1161/ CIRCULATIONAHA.118.035132

11. Tassano E, Buttgereit J, Bader M, et al. Genotype-Phenotype Correlation of 2q37 Deletions Including NPPC Gene Associated with Skeletal Malformations. PLoS One. 2013 Jun 21; 8(6): e66048. https://doi. org/10.1371/journal.pone.0066048

12. Hirota K, Furuya M, Morozumi N, et al. Exogenous C-type natriuretic peptide restores normal growth and prevents early growth plate closure in its deficient rats. PLoS One. 2018 Sep 20; 13(9): e0204172. https:// doi.org/10.1371/journal.pone.0204172

13. Nakao K, Osawa K, Yasoda A, et al. The Local CNP/GC-B system in growth plate is responsible for physiological endochondral bone growth. Sci Rep. 2015; 5: 10554. https://doi.org/10.1038/srep10554

14. Jaubert J, Jaubert F, Martin N, et al. Three new allelic mouse mutations that cause skeletal overgrowth involve the natriuretic peptide receptor $\mathrm{C}$ gene (Npr3). Proc Natl Acad Sci. U S A. 1999 Aug 31; 96(18): 10278-83. https://doi.org/10.1073/pnas.96.18.10278

15. Yasoda A, Komatsu Y, Chusho H, et al. Overexpression of CNP in chondrocytes rescues achondroplasia through a MAPK-dependent pathway. Nat Med. 2004 Jan; 10(1): 80-6. https://doi.org/10.1038/nm971

16. Wagner BM, Robinson JW, Lin YW, et al. Prevention of guanylyl cyclase-B dephosphorylation rescues achondroplastic dwarfism. JCI Insight. 2021 Mar 30: 147832. https://doi.org/10.1172/jci.insight.147832
17. Fujii T, Hirota K, Yasoda A, et al. Rats deficient C-type natriuretic peptide suffer from impaired skeletal growth without early death. PLoS One. 2018 Mar 22; 13(3): e0194812. https://doi.org/10.1371/journal.pone.0194812 18. Amano N, Kitoh H, Narumi S, et al. A novel NPR2 mutation (p. Arg388Gln) in a patient with acromesomelic dysplasia, type Maroteaux. Clin Pediatr Endocrinol. 2020; 29(3): 99-103. https://doi.org/10.1297/ cpe. 29.99

19. Khan S, Basit S, Khan MA, et al. Genetics of human isolated acromesomelic dysplasia. Eur J Med Genet. 2016 Apr; 59(4): 198-203. https://doi.org/10.1016/j.ejmg.2016.02.011

20. Wang W, Song MH, Miura K, et al. Acromesomelic dysplasia, type maroteaux caused by novel loss-of-function mutations of the NPR2 gene: Three case reports. Am J Med Genet A. 2016 Feb; 170A(2): 426434. https://doi.org/10.1002/ajmg.a.37463

21. Olney RC, Bükülmez H, Bartels CF, et al. Heterozygous mutations in natriuretic peptide receptor-B (NPR2) are associated with short stature. J Clin Endocrinol Metab. 2006 Apr; 91(4): 1229-32. https:// doi.org/10.1210/jc.2005-1949

22. Vasques GA, Amano N, Docko AJ, et al. Heterozygous mutations in natriuretic peptide receptor-B (NPR2) gene as a cause of short stature in patients initially classified as idiopathic short stature. J Clin Endocrinol Metab. 2013 Oct; 98(10): E1636-44. https://doi.org/10.1210/jc.2013-2142

23. Bocciardi R, Ravazzolo R. C-type natriuretic peptide and overgrowth. Endocr Dev. 2009; 14: 61-6. https://doi.org/10.1159/000207477

24. Miura K, Kim OH, Lee HR, et al. Overgrowth syndrome associated with a gain-of-function mutation of the natriuretic peptide receptor 2 (NPR2) gene. Am J Med Genet A. 2014 Jan; 164A(1): 156-63. https:// doi.org/10.1002/ajmg.a.36218

25. Olney RC, Permuy JW, Prickett TC, et al. Amino-terminal propeptide of C-type natriuretic peptide (NTproCNP) predicts height velocity in healthy children. Clin Endocrinol (Oxf). 2012 Sep; 77(3): 416-22. https://doi.org/10.1111/j.1365-2265.2012.04392.x

26. Diemar SS, Lylloff L, Rønne MS, et al. Reference intervals in Danish children and adolescents for bone turnover markers carboxy-terminal cross-linked telopeptide of type I collagen ( $\beta$-CTX), pro-collagen type I N-terminal propeptide (PINP), osteocalcin (OC) and bone-specific alkaline phosphatase (bone ALP). Bone. 2021 May; 146: 115879. https:// doi.org/10.1016/j.bone.2021.115879

27. Bayer M. Reference values of osteocalcin and procollagen type I $\mathrm{N}$-propeptide plasma levels in a healthy Central European population aged 0-18 years. Osteoporos Int. $2014 \mathrm{Feb}$; 25(2): 729-36. https://doi. org/10.1007/s00198-013-2485-4

28. Shao J, Zhou SS, Qu Y, et al. Correlation between bone turnover and metabolic markers with age and gender: a cross-sectional study of hospital information system data. BMC Musculoskelet Disord. 2020 Sep 10; 21(1): 603. https://doi.org/10.1186/s12891-020-03610-w

29. Gajewska J, Klemarczyk W, Ambroszkiewicz J, et al. Associations between IGF-I, IGF-binding proteins and bone turnover markers in prepubertal obese children. J Pediatr Endocrinol Metab. 2015 May; 28(5-6): 563-9. https://doi.org/10.1515/jpem-2014-0326

30. Rauchenzauner M, Schmid A, Heinz-Erian P, et al. Sex- and age-specific reference curves for serum markers of bone turnover in healthy children from 2 months to 18 years. J Clin Endocrinol Metab. 2007 Feb; 92(2): 443-9. https://doi.org/10.1210/jc.2006-1706

31. Ladang A, Rousselle O, Huyghebaert L, et al. Parathormone, bone alkaline phosphatase and 25-hydroxyvitamin D status in a large cohort of 1200 children and teenagers. Acta Clin Belg. 2020 May 22: 1-6. https://doi.org/10.1080/17843286.2020.1769285

32. Vincent A, Souberbielle JC, Brauner R. Comparison of two bone markers with growth evolution in 74 girls with central precocious puberty. BMC Pediatr. 2018 Jul 9; 18(1): 224. https://doi.org/10.1186/ s12887-018-1194-8

33. Chlebna-Sokół D, Konstantynowicz J, Abramowicz P, et al. Evidence of a significant vitamin D deficiency among 9-13-year-old Polish children: results of a multicentre study. Eur J Nutr. 2019 Aug; 58(5): 2029-2036.4 https://doi.org/10.1007/s00394-018-1756-4

34. Olney RC, Salehi P, Prickett TC, et al. Dynamic response of C-type natriuretic peptide and its aminoterminal propeptide (NTproCNP) to growth hormone treatment in children with short stature. Clin Endocrinol (Oxf). 2016 Oct; 85(4): 561-8. https://doi.org/10.1111/ cen. 13103

35. Kondo E, Yasoda A, Fujii T, et al. Increased Bone Turnover and Possible Accelerated Fracture Healing in a Murine Model With an Increased Circulating C-Type Natriuretic Peptide. Endocrinology. 2015 Jul; 156(7): 2518-29. https://doi.org/10.1210/en.2014-1801

36. Bükülmez H, Khan F, Bartels CF, et al. Protective effects of C-type natriuretic peptide on linear growth and articular cartilage integrity 
in a mouse model of inflammatory arthritis. Arthritis Rheumatol. 2014 Jan; 66(1): 78-89. https://doi.org/10.1002/art.38199

37. Prickett TC, Hector-Taylor J, Olney RC, et al. Acute inflammation in young children inhibits C-type natriuretic peptide. Pediatr Res. 2013 Aug; 74(2): 191-5. https://doi.org/10.1038/pr.2013.92

38. Topçu S, Özhan B, Alkan A, et al. Plasma Amino-Terminal Propeptide of C-Type Natriuretic Peptide Concentration in Normal-Weight and Obese Children. J Clin Res Pediatr Endocrinol. 2017 Dec 15; 9(4): 308-314. https://doi.org/10.4274/jcrpe.4543

39. Olney RC, Prickett TC, Espiner EA, et al. C-type natriuretic peptide plasma levels are elevated in subjects with achondroplasia, hypochondroplasia, and thanatophoric dysplasia. J Clin Endocrinol Metab. 2015 Feb; 100(2): E355-9. https://doi.org/10.1210/jc.2014-2814
40. Klag KA, Horton WA. Advances in treatment of achondroplasia and osteoarthritis. Hum Mol Genet. 2016 Apr 15; 25(R1): R2-8. https://doi. org/10.1093/hmg/ddv419

41. Savarirayan R, Tofts L, Irving M, et al. SAT-LB18 A Randomized Controlled Trial of Vosoritide in Children With Achondroplasia. J Endocr Soc. 2020 May 8; 4(Suppl 1): SAT-LB18. https://doi.org/10.1210/ jendso/bvaa046.2081

42. Hisado-Oliva A, Ruzafa-Martin A, Sentchordi L, et al. Mutations in C-natriuretic peptide (NPPC): a novel cause of autosomal dominant short stature. Genet Med. 2018 Jan; 20(1): 91-97. https:/doi.org/10.1038/ gim. 2017.66

43. Ueda Y, Hirota K, Yamauchi I, et al. Is C-type natriuretic peptide regulated by a feedback loop? A study on systemic and local autoregulatory effect. PLoS One. 2020 Oct 1; 15(10): e0240023. https:// doi: 10.1371/journal.pone.0240023. eCollection 2020 